\title{
Evidencias de procesos de alteración hidrotermal en cuerpos ígneos del municipio de Pajarito, flanco este de la cordillera Oriental (Colombia)
}

\author{
Angélica Julieth González-Preciado ${ }^{* *}$; Sofía Durán-González ${ }^{1}$; Jorge Eliecer Mariño-Martínez $^{1}$
}

Forma de citar: González-Preciado, A.J.; Durán-González, S.; Mariño-Martínez, J.E. (2021). Evidencias de procesos de alteración hidrotermal en cuerpos ígneos del municipio de Pajarito, flanco este de la cordillera Oriental (Colombia). Boletín de Geología, 43(3), 87-105. https://doi.org/10.18273/revbol.v43n3-2021004

\begin{abstract}
Resumen
En el municipio de Pajarito (departamento de Boyacá - Colombia), en un área de $48 \mathrm{~km}^{2}$ y sobre el flanco este de la cordillera Oriental, aflora una serie de cuerpos intrusivos máficos, que regionalmente están orientados en dirección N-S y se hospedan en rocas sedimentarias de edad Cretácico inferior. De estos cuerpos se estudiaron seis intrusiones: cinco cuerpos laminares, definidos como intrusión 1 a intrusión 5, y un sexto cuerpo de mayor tamaño definido como Cuerpo Ígneo Principal (CIP). Estas rocas están dominadas por texturas faneríticas a porfídicas, con cristales de piroxeno y plagioclasa, y se encuentran intruyendo pelitas que en la zona de contacto con los intrusivos varían a metalimolitas y argilitas. Los datos de campo y petrográficos sugieren que estas intrusiones fueron alteradas por acción de soluciones hidrotermales que generaron como consecuencia del intercambio químico, texturas de reemplazamiento y dos asociaciones paragenéticas: la paragénesis sericita pirita - calcita, relacionada a un $\mathrm{pH}$ entre neutro a ligeramente ácido; y la paragénesis calcita - clorita - epidota - actinolita asociada a zonas de pH neutro a básico. De igual forma, las soluciones hidrotermales podrían estar relacionadas con una hipotética mineralización, como producto del proceso de lixiviación y enriquecimiento de elementos metálicos a partir de su paso por los cuerpos ígneos, y su consecuente precipitación en una trampa geoquímica.
\end{abstract}

Palabras clave: Petrografía; Alteración hidrotermal; Intrusiones; Cuerpo ígneo; Pajarito.

\section{Hydrothermal evidence in igneous intrusions in Pajarito, on the East flank of the Eastern Cordillera (Colombia)}

\begin{abstract}
In the locality of Pajarito (Boyacá Department - Colombia), in an area of $48 \mathrm{~km}^{2}$ and on the eastern flank of the Eastern Cordillera, a series of mafic intrusive bodies emerge, that are regionally oriented in a NS direction and are hosted in sedimentary rocks of Lower Cretaceous age. Six intrusions were studied of these bodies: five laminar bodies, defined as Intrusion 1 to Intrusion 5, and a sixth larger body defined as Main Igneous Body or 'CIP' (by its acronym in Spanish). These rocks are dominated by phaneritic to porphyritic textures, with crystals of: pyroxene and plagioclase, and are found intruding pelites that, in the area of contact with the intrusives, vary to metalimolites and argillites. The field and petrographic data suggest that these intrusions were altered by the action of hydrothermal solutions that generated as a consequence of chemical exchange, replacement textures and two paragenetic associations: the sericite - pyrite - calcite paragenesis, related to a $\mathrm{pH}$ between neutral to slightly acid; and calcite - chlorite - epidote - actinolite paragenesis associated with areas of neutral to basic $\mathrm{pH}$. Similarly, hydrothermal solutions could be related to a hypothetical mineralization, as a product of the process of leaching and enrichment of metallic elements from their passage through igneous bodies, and their consequent precipitation in a geochemical trap.
\end{abstract}

Keywords: Petrography; Hydrothermal alteration; Intrusions; Igneous body; Pajarito.

${ }^{1}$ Escuela de Ingeniería Geológica, Universidad Pedagógica y Tecnológica de Colombia, Sogamoso, Colombia. (*) angelica.gonzalez01@uptc.edu.co; sofia.duran@uptc.edu.co; jorge.marino@uptc.edu.co 


\section{Introducción}

La evolución tectónica de los Andes del Norte es considerada como una orogenia típica de tipo acrecional, relacionada con diferentes fases de extensión y compresión, dentro de un sistema de subducción activa desde el Jurásico (Ramos, 2009). La extensión en el territorio colombiano, durante el Cretácico temprano, fue generada por un sistema de rift que causó la reactivación del Sistema de Fallas de Guaicáramo durante el Berriasiano, lo que originó una cuenca de graben en la parte este de la cordillera Oriental, donde se depositaron más de $3 \mathrm{~km}$ de sedimentos marinos; posteriormente, los segmentos de mayor subsidencia de la cuenca fueron emplazados por un grupo de pequeñas intrusiones máficas, favorecidas por algunas fallas principales, que pudieron facilitar el proceso de ascenso magmático (Dengo y Covey, 1993; Pindell y Erikson, 1994; Sarmiento-Rojas et al., 2006; Vásquez et al., 2010; Tesón et al., 2013; Zapata et al., 2019). Estos cuerpos máficos se encuentran actualmente ubicados en ambos flancos de la cordillera Oriental, distribuidos entre los departamentos de Cundinamarca, Boyacá y Casanare. Comprenden, entre otros cuerpos, las intrusiones de Guaquimay, Cáceres, La Corona, Pacho, Pajarito y Rodrigoque, y están emplazados de forma no coetánea entre 136 y 74 Ma, con diferencias geoquímicas considerables y dos series composicionales principales entre alcalinas y toleíticas (Fabre y Delaloye, 1983; Navarrete-Rodríguez et al., 2002; Vásquez et al., 2010; Canchón-Acuña et al., 2014).

El cuerpo ígneo de Pajarito (denominado en este estudio Cuerpo Ígneo Principal (CIP)) fue estudiado y nombrado por primera vez por el Servicio Geológico Colombiano, quien denominó con este nombre a una intrusión que aflora al noroccidente del área urbana de Pajarito (departamento de Boyacá); este cuerpo intruye localmente las rocas sedimentarias de edad Cretácico inferior pertenecientes a la Formación Lutitas de Macanal (Ulloa y Rodríguez, 1981). Las rocas del CIP han sido clasificadas como melagabros piroxénicos hornbléndicos o piroxeno - hornblenditas, desde el punto de vista petrográfico y geoquímico, donde es mencionada una reducida serie de alteraciones, relacionadas con procesos hidrotermales potenciales (Moreno-Murillo et al., 2007; Vásquez y Altenberger, 2005).

Aunque estudios anteriores han cartografiado y descrito el CIP, solo han sido reportados un par de cuerpos laminares menores en Moreno-Murillo et al. (2007) (Figura 1), sin la caracterización de las diferencias texturales de alteración, ni los minerales relacionados con la circulación de soluciones hidrotermales. De esa manera, a partir de observaciones en campo, los autores de esta investigación pretenden definir la ubicación de un conjunto de cuerpos laminares pequeños con características ígneas, además de realizar análisis e interpretaciones macroscópicas y petrográficas en cinco cuerpos laminares, el CIP y muestras de la roca caja, que evidencien la influencia de las soluciones hidrotermales que modificaron los caracteres de la etapa magmática sobre las rocas muestreadas, y posiblemente estén relacionadas con un enriquecimiento en elementos metálicos, como consecuencia de su circulación a través de las rocas ígneas.

\section{Contexto geológico del área de estudio}

En el territorio colombiano, durante el Triásico tardío - Jurásico, predominó una fase extensional de rifting y actividad magmática, marcada por tres eventos asociados principalmente a pulsos de adelgazamiento de la corteza terrestre, que probablemente estén relacionados con la rotura del supercontinente Pangea; seguido por la formación de un amplio sistema de cuencas asimétricas (cuencas de backarc), que se extendieron en la parte central de la actual cordillera Oriental. En el Jurásico superior - Cretácico inferior inicia la depositación de una espesa secuencia sedimentaria (Sarmiento-Rojas et al., 2006; Vásquez y Altenberger, 2005; Jaillard et al., 1990). Consecutivamente, ocurrieron dos eventos importantes, donde se generaron áreas de máximo adelgazamiento de la corteza en la cuenca cordillera Oriental durante el Cretácico temprano, que coinciden con emplazamientos de pequeñas intrusiones máficas alcalinas y toleíticas. El primer evento, durante el Berriasiano - Hauteriviano (144-127 Ma), estuvo relacionado con un amplio sistema de graben con dirección NNE-SSW, desarrollado por la reactivación de paleo-fallas normales asociadas al presistema de fallas de Guaicáramo. El segundo episodio de adelgazamiento de la corteza, en el Aptiano - Albiano temprano (121-102 Ma), se caracterizó por la formación de una amplia cuenca, que se extendió hacia el valle superior del Magdalena (cuenca Tablazo - Magdalena y Cocuy) (Sarmiento-Rojas et al., 2006).

Durante el Cenozoico, concretamente en el Eoceno, los eventos de compresión principales sobre la cordillera Oriental inician con episodios de perturbación orogénica preandina; finalmente, en el Mioceno, se da lugar a la orogenia Andina con un levantamiento intermitente y variable. La cordillera Oriental empieza a tomar forma, mostrando una megasecuencia cretácica 
marina, que representa un gran ciclo de transgresión - regresión, con cambios abruptos de espesor como testimonio de la subsidencia tectónica diferencial; la cordillera termina limitada por plegamientos agudos, fallas inversas de fuerte ángulo o fallas de rumbo (Sarmiento-Rojas et al., 2006; Irving, 1971).

Localmente, la configuración morfológica y estructural de la cordillera Oriental en el área de estudio muestra una zona de extensas estructuras plegadas como consecuencia de esfuerzos de tipo compresional, que responden al control estructural de la falla inversa activa Chámeza - Pajarito, perteneciente al sistema de fallas de Guaicáramo al oriente (Piraquive et al., 2011). La configuración geomorfológica variada con pendientes estructurales que pertenecen a la Formación Lutitas de Macanal y los datos estructurales cambiantes por la intensa actividad tectónica manifiestan dos estructuras principales al noroeste y suroeste de la zona de estudio: el sinclinal del Desespero, una estructura regional simétrica de dirección aproximada $\mathrm{N} 30^{\circ} \mathrm{E}$ y una extensión de 90 km de largo (INGEOMINAS, 2010); y el anticlinal de Magavita, estructura cortada por la vía secundaria que conduce de Pajarito a la vereda Magavita Alta con dirección aproximada $\mathrm{N} 40^{\circ} \mathrm{E}$ (Durán-González y González-Preciado, 2019).

La ubicación del área de estudio se ilustra en la Figura 1, en esta, se manifiestan principalmente las formaciones Lutitas de Macanal (Kilm), Areniscas de Las Juntas (Kiaj), Fómeque (Kif), el cuerpo intrusivo de Pajarito (Kiip) y cuerpos cuaternarios al costado del río Cusiana, donde se ubica la cabecera municipal de Pajarito. Y en un segmento de menor amplitud las formaciones Une (Kiu), Chipaque (Ksc) y Grupo Palmichal (TKp).

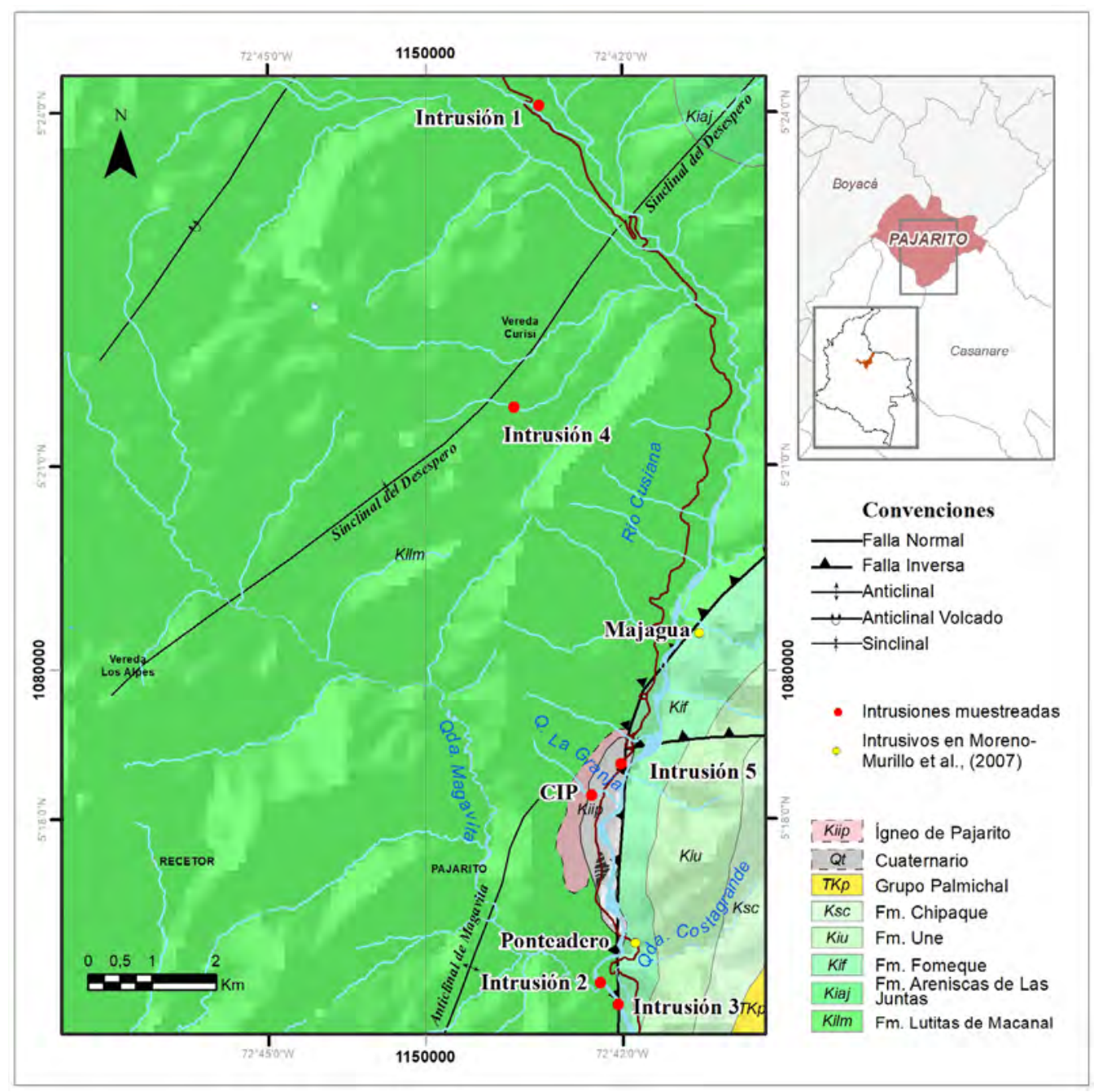

Figura 1. Localización del área de estudio. La figura resume las ubicaciones de las intrusiones 1-5 y el cuerpo ígneo de Pajarito, además de los dos cuerpos mencionados en Moreno-Murillo et al., (2007). Modificado de Ulloa y Rodríguez (1981) y Ulloa et al. (2001). 


\section{Formación Lutitas de Macanal (Kilm)}

Según Piraquive et al. (2011), la Formación Lutitas de Macanal de edad Berriasiano temprano - Hauteriviano temprano está representada localmente por una gruesa secuencia de lodolitas negras, intercaladas con areniscas, limolitas y ocasionalmente calizas, con un espesor medido a partir de corte geológico de $1200 \mathrm{~m}$. Los ambientes deposicionales muestran una somerización de esta unidad hacia el este, donde facies de grano grueso y geometrías lobulares contrastan con litologías muy finas de depósitos hemipelágicos que se desarrollan hacia el occidente, estas facies de grano fino representan depositación bajo condiciones submarinas que evolucionan de un ambiente de plataforma interna - externa a un ambiente de abanicos deltaicos cerca de la línea de costa.

\section{Formación Areniscas de Las Juntas}

Representada localmente por un conjunto de $270 \mathrm{~m}$ de areniscas cuarzosas, fuertemente cementadas, de grano fino y estratificación masiva, e intercalaciones de lutitas negras que afloran en el extremo noreste del área de estudio con una morfología abrupta. La edad de esta formación ha sido considerada como Hauteriviano tardío, depositada en ambientes marinos litorales con afluencias deltaicas (Ulloa y Rodríguez, 1981; Piraquive et al., 2011). Sin embargo, en el sector sur del área de estudio, la Formación Areniscas de Las Juntas está ausente por actividad de la falla de Chámeza Pajarito, que pone en contacto las formaciones Lutitas de Macanal y Fómeque.

\section{Formación Fómeque}

La Formación Fómeque está ubicada al costado este del río Cusiana, en contacto con la falla Chámeza - Pajarito, y la Formación Une. Se caracteriza por una topografía suavemente ondulada, constituida por capas masivas de arcillolitas arenosas grises con intercalaciones de lutitas negras, margas y areniscas, de espesor variable alrededor de $560 \mathrm{~m}$. Indica un ambiente de depósito marino de aguas someras y circulación restringida, de edad Barremiano medio - Albiano inferior (Ulloa y Rodríguez, 1981; Piraquive et al., 2011).

\section{Cuerpo ígneo de Pajarito (Kiip)}

El cuerpo ígneo de Pajarito, descrito como varias apófisis de lamprófiros y pequeños diques, se encuentra ubicado al norte de la población de Pajarito, intruyendo las rocas sedimentarias de la Formación Lutitas de Macanal, con cuerpos que pueden llegar a tener hasta 30 m de espesor (Ulloa y Rodríguez, 1981; Vásquez y Altenberger, 2005). El CIP está ubicado sobre la quebrada La Granja, dispuesto en forma de silo y con una expresión morfológica alargada, con una orientación NE-SW no muy notoria en las fotografías aéreas. La roca macroscópicamente es de color gris verdoso a verde, de cristalinidad holocristalina, inequigranular, de grano fino en la zona externa del silo a grueso en el núcleo, con fenocristales oscuros y textura porfirítica. Microscópicamente, se reconocen cristales de piroxenos (pigeonite, augita y diópsido), anfíboles (kaersutite, pargasite, tschermakite, actinolita y tremolita) y plagioclasas (albita), y minerales de alteración como calcita, epidota y pirita, que sugieren metamorfismo de bajo grado o hidrotermalismo. Estas rocas son clasificadas como piroxeno - hornblenditas o melagabros piroxénicos hornbléndicos (Vásquez y Altenberger, 2005; RoaCastro y Rojas-Avella, 1992; Moreno-Murillo et al., 2007). Tanto las rocas ígneas como las rocas encajantes presentan evidencias de alteración hidrotermal, lo que indica que con posterioridad a la intrusión ocurrieron fenómenos hidrotermales (Ulloa y Rodríguez, 1981; Saylor et al., 2012).

Las rocas máficas de Pajarito, de acuerdo con Vásquez et al. (2010), sugieren un origen alcalino, relacionado con fundidos primitivos fuertemente enriquecidos con tierras raras (REE). Ulloa y Rodríguez (1981) sugieren que el origen de los diques y apófisis se puede atribuir a los efectos tardíos de la intrusión de un batolito, localizado posiblemente en las cercanías de Aguazul, soportado por la presencia de una anomalía geofísica relacionada. Fabre y Delaloye (1983), mediante datación $\mathrm{K} / \mathrm{Ar}$ en roca total para una muestra del gabro, calculan una edad de $118 \pm 6,4 \mathrm{Ma}$, mientras que Vásquez et al. (2010), mediante datación ${ }^{40} \mathrm{Ar} /{ }^{39} \mathrm{Ar}$ sobre cristales de hornblenda, determinan una edad media de 120,5 $\pm 0,6 \mathrm{Ma}$, ambas edades comprendidas en el Aptiano, que representa probablemente la edad de la intrusión del CIP.

\section{Metodología}

La propuesta metodológica adoptada comprende cuatro fases secuenciales. En la primera fase se realizó una recopilación bibliográfica de la información geocientífica y cartográfica del área, donde se proyectó el muestreo y búsqueda de información petrográfica. En una segunda fase de visita a campo se revisó la 
cartografía del área que permitió la identificación y muestreo del ígneo principal (muestras Pj-cip1, Pj-cip2, Pj-m3 y Pj-m4) y de los intrusivos más pequeños en los alrededores (muestras de los intrusivos $\mathrm{Pj}$-ia, $\mathrm{Pj}$-ib, $\mathrm{Pj}$ ic, Pj-id, Pj-ie y muestras de roca caja Pj-ma). En total se tomaron diez muestras para análisis macroscópicos y microscópicos. En la tercera fase se describieron las muestras y se hicieron los análisis macroscópicos, seguido de la fabricación de las secciones delgadas de ocho de las muestras (muestras $\mathrm{Pj}$-ia, $\mathrm{Pj}$-ma, Pj-ib, Pj-ic, Pj-cip1, Pj-cip2, Pj-m3 y Pj-m4); finalmente, se realizaron análisis microscópicos en el laboratorio de petrografía de la Universidad Pedagógica y Tecnológica de Colombia - Sogamoso, con objeto de determinar minerales relacionados con procesos magmáticos e hidrotermales, texturas, paragénesis y consideraciones preliminares de los tipos de alteración hidrotermal presentes. Se utilizó un microscopio binocular petrográfico de luz polarizante marca MEIJI modelo MT9920, la guía de identificación de minerales de alteración de Thompson y Thompson (1996), la tabla de clasificación macroscópica de Huang (1991) y el diagrama de clasificación microscópica para gabros de Streckeisen (1976). En la fase final de resultados y discusión de resultados se exponen las interpretaciones finales, que comprenden los análisis petrográficos y evidencias de alteraciones, como producto de procesos posmagmáticos sobre las rocas intrusivas y los cuerpos laminares identificados.

\section{Resultados}

\section{Localización}

El área de estudio, comprendida entre las planchas 192IIID, 192IVC, 211IB y 211IIA, incluye gran parte de la jurisdicción municipal de Pajarito (Boyacá) (Figura 1). Se puede tener acceso al área por medio de la vía principal Sogamoso - Yopal y parcialmente por la vía secundaria que conduce desde la vereda Curisí hasta la vereda Los Alpes. Localmente, el flanco este de la cordillera Oriental presenta una geomorfología de lomerío correspondiente a litologías de rocas blandas con intensa actividad denudativa fluvio-erosional. La red hidrográfica se encuentra dominada por el curso del río Cusiana, el cual está controlado estructuralmente por la falla Chámeza - Pajarito. El patrón de drenaje es predominantemente subdendrítico con regiones muy localizadas donde cambia a un patrón subparalelo (Moreno-Murillo et al., 2007).

En este estudio se caracterizaron seis cuerpos intrusivos, los cuales se encuentran emplazados en las rocas sedimentarias de la Formación Lutitas de Macanal, al occidente del río Cusiana. Las primeras cinco intrusiones encontradas en la fase de campo fueron nombradas consecutivamente, teniendo en cuenta el orden en que se encontraron. El cuerpo número seis fue definido y caracterizado como Cuerpo Ígneo Principal (CIP) o cuerpo ígneo de Pajarito de acuerdo con Moreno-Murillo et al. (2007) y Ulloa y Rodríguez (1981) (Figura 1-4 y Tabla 1). Las intrusiones 1 a 4 son reportadas por primera vez en este estudio.

Tabla 1. Localización de intrusiones.

\begin{tabular}{|c|c|c|c|}
\hline Intrusiones & \multicolumn{2}{|c|}{ Coordenadas X, Y } & Ubicación \\
\hline Intrusión 1 & 1151396 & 1089164 & $\begin{array}{l}\text { Curisí, puente sobre } \\
\text { el río Cusiana }\end{array}$ \\
\hline Intrusión 2 & 1152637 & 1075095 & $\begin{array}{l}\text { Inter. Q. Magavita - } \\
\text { río Cusiana }\end{array}$ \\
\hline Intrusión 3 & 1152363 & 1075434 & $\begin{array}{c}\text { Inter. Q. Costa } \\
\text { Grande - río Cusiana }\end{array}$ \\
\hline Intrusión 4 & 1151005 & 1084434 & $\begin{array}{c}\text { Vía Curisí - Los } \\
\text { Alpes }\end{array}$ \\
\hline Intrusión 5 & 1152686 & 1078855 & $\begin{array}{c}\text { Vía Sogamoso - } \\
\text { Yopal }\end{array}$ \\
\hline CIP & 1152228 & 1078365 & Quebrada La Granja \\
\hline
\end{tabular}

\section{Aspectos macroscópicos}

En el área de estudio, los cuerpos intrusivos se encontraron dispuestos en formas laminares, comúnmente paralelas al sentido de la estratificación de las rocas sedimentarias (silos). En algunos afloramientos no se aprecia correctamente su forma o disposición, dado que fueron expuestos por la acción erosiva de las quebradas presentes en el sector. La fuerte expresión morfológica de los cuerpos cristalinos, en conjunto con su coloración clara a verdosa, permite diferenciarlos de las rocas lutíticas que están intruyendo. En general, las intrusiones 1 a 5 muestran una marcada oxidación en la superficie como proceso de meteorización, condicionado por la dinámica fluvial en un clima tropical húmedo.

El primer cuerpo, denominado intrusión 1 (Figura 2A, 2B) está ubicado en la vereda Curisí, dispuesto con respecto a la estratificación de rocas sedimentarias en forma de silo, con un espesor aproximado de $10 \mathrm{~m}$. La roca encajante es de textura pelítica, color gris oscuro y estratificación plano paralela; evidencia un bajo grado de metamorfismo de contacto dado su aspecto pizarroso-laminado que, de acuerdo con interpretaciones macroscópicas realizadas sobre la muestra Pj-ma, se 
clasificó como argilita. La roca ígnea presenta en la muestra $\mathrm{Pj}$-ia una textura aparentemente porfídica con cristales de plagioclasa, piroxenos y calcopirita, además de claras evidencias de alteración hidrotermal basada en la presencia de minerales arcillosos de reemplazamiento y la reacción positiva ante el contacto con el ácido. Finalmente, fueron identificadas varias familias de diaclasas que ocasionalmente están rellenas de venas compuestas por sílice. El contacto entre el silo y la roca caja es neto (Figura 2A).

La intrusión 2 (Figura 2C) se ubica en la confluencia entre la quebrada Magavita y el río Cusiana; no es clara la exposición de la roca encajante, por lo tanto, no se puede caracterizar el cuerpo intrusivo como silo o dique, sin embargo, se aprecia el dominio de una familia de diaclasas en el cuerpo caracterizado. Superficialmente, la roca presenta oxidación color café-rojizo. Macroscópicamente (muestra Pj-ib), la roca aparenta una textura porfídica, con una masa microcristalina, cristales inmersos de epidota y fenocristales de plagioclasa determinados según la forma; sin embargo, es evidente la alteración hidrotermal por la presencia de minerales arcillosos que tienden a reemplazar los feldespatos (Figura 2D).

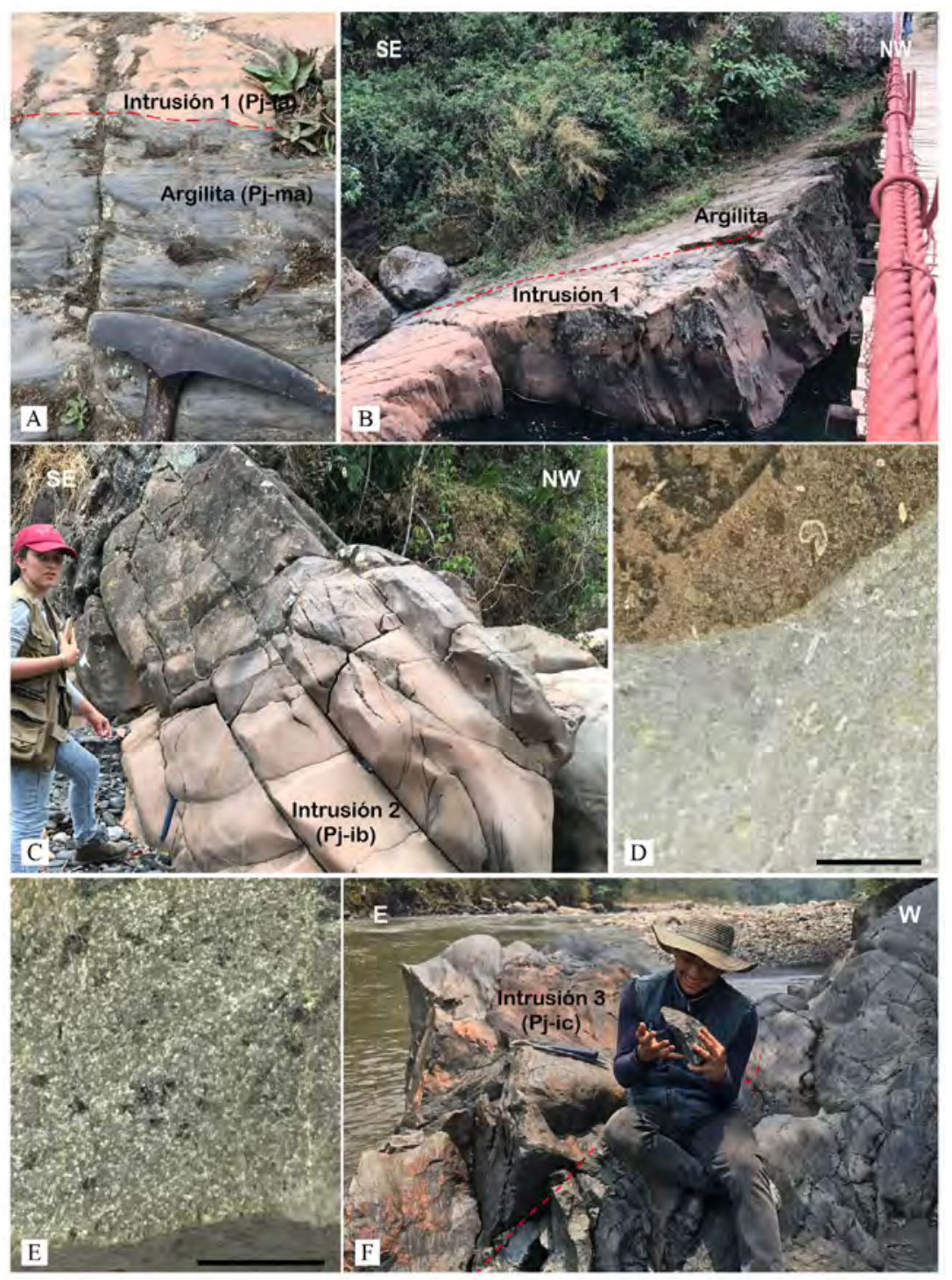

Figura 2. Fotografías de las intrusiones 1 a 3. A-B. Intrusión 1, la roca cristalina expuesta es de color rojizo en superficie oxidada y se delinea en color rojo el contacto con la roca encajante (rocas argilíticas de color gris oscuro). C. Intrusión 2, la roca expone coloración rojiza y varias fracturas paralelas. D. Intrusión 2, textura porfídica de la muestra Pj-ib, se observa alteración de fenocristales evidenciada por el cambio de color. E. Intrusión 3, textura porfídica de la muestra Pj-ic. F. Intrusión 3, cuerpo intrusivo en contacto irregular con rocas lutíticas oscuras. 
El cuerpo intrusión 3 está ubicado próximo a la confluencia de la quebrada Costa Grande con el río Cusiana (Figura 2F). En general, la tendencia del cuerpo intrusivo con respecto a la estratificación de la roca caja en apariencia es paralela. El contacto entre el cuerpo intrusivo y la roca caja es irregular, lo que evidencia un incipiente metamorfismo. La muestra Pjic (Figura 2E), correspondiente al cuerpo intrusivo, es de color verde pálido a grisáceo, con cristales oscuros dispersos que dan apariencia moteada a la roca. Macroscópicamente los minerales se identificaron con base en las formas aparentes; se diferenciaron plagioclasa, hornblenda, piroxenos y pirita.

La intrusión 4, muestra Pj-id (Figura 3A) está ubicada en la vía secundaria que de la vereda Curisí lleva a la vereda Los Alpes. Este cuerpo laminar se encuentra emplazado en forma de silo con un espesor aproximado de $1 \mathrm{~m}$. En el sector, el cuerpo presenta un alto grado de meteorización, exponiendo pocas superficies frescas de coloración gris oliva claro, donde es posible identificar una textura porfídica y minerales como plagioclasa, epidota y pirita (Figura 3B). La roca caja de textura pelítica no manifiesta alteración por metamorfismo.

El intrusivo 5, muestra Pj-ie, es el cuerpo cristalino más próximo al CIP, ubicado en el talud de la vía principal, emplazado en forma de silo con un espesor aproximado de $3 \mathrm{~m}$. La roca encajante no manifiesta ningún grado de metamorfismo (Figura 3D). El afloramiento de este cuerpo expone una roca cristalina dura, débilmente meteorizada con coloración superficial de amarillenta a gris-verdosa en una superficie fresca y minerales secundarios dispersos en la roca, como pirita, yeso, siderita y cuarzo, ubicados sobre algunas fracturas superficiales. Macroscópicamente la muestra presenta textura porfídica con semejanzas al cuerpo intrusivo 2. Se identifican minerales primarios como plagioclasa y piroxeno; y de alteración como clorita y epidota (Figura 3C).

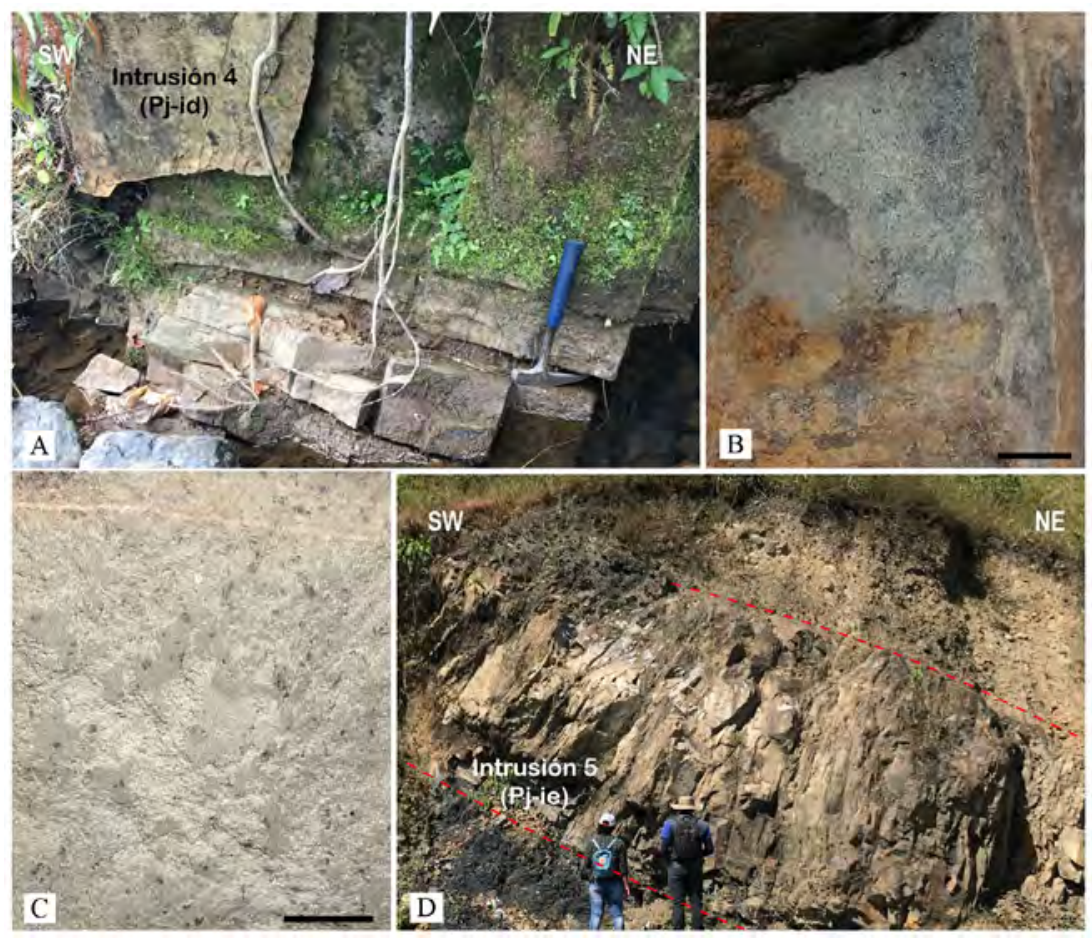

Figura 3. Fotografías de las intrusiones 4-5. A. Intrusión 4, roca altamente meteorizada, con fracturamiento paralelo frecuente. B. Intrusión 4, textura de la muestra $\mathrm{Pj}$-id. C. Intrusión 5, textura de la muestra $\mathrm{Pj}$-ie. D. Intrusión 5 aflora en la vía principal Sogamoso - Yopal, los contactos con la roca caja están señalados en color rojo.

Las rocas que componen el CIP (Figura 4A, 4B) se encuentran en un tramo de la quebrada La Granja, dispuestas en forma de silo, además, se presenta una intensa fracturación en toda la masa cristalina. Se identificaron cuatro familias de diaclasas dominantes con direcciones $\mathrm{N} 56^{\circ} \mathrm{W} / 30^{\circ} \mathrm{NE}, \quad \mathrm{N} 36^{\circ} \mathrm{E} / 79^{\circ} \mathrm{SE}$, $\mathrm{N} 23^{\circ} \mathrm{E} / 84^{\circ} \mathrm{NW}$ y $\mathrm{N} 23^{\circ} \mathrm{W} / 25^{\circ} \mathrm{NE}$, y continuos planos de falla en los que se determinó una dirección aproximada $\mathrm{N} 66^{\circ} \mathrm{E} / 70^{\circ} \mathrm{SE}$. En este caso, se diferencia una zonación de las rocas sedimentarias que circundan el intrusivo. 
Primero, en contacto con las rocas plutónicas, se observó una roca de color verde claro, aspecto homogéneo y con evidencia de la acción de soluciones hidrotermales por la alteración en los cristales (muestra Pj-m4, Figura 4C). Segundo, la zonación continúa y finaliza mostrando una franja de roca de color gris moteada, definida a partir de la muestra Pj-m3 como metalimolita u hornfelsa (Figura 4D), presente en las rocas lutíticas de la Formación Lutitas de Macanal. La roca ígnea internamente presenta una zonación basada en el tamaño de los cristales visualizados en las muestras Pj-cip1 y Pj-cip2, según la ubicación periférica o central, respectivamente. La muestra Pj-cip1 (Figura 4C) expone cristales que se pueden identificar a simple vista, presenta una coloración gris verdosa y moteada, textura fanerítica y grado de cristalinidad holocristalino. Los cristales identificados son hornblenda, piroxeno, clorita, feldespatos, epidota y pirita. La muestra Pj-cip2 (Figura 4D) tiene un aspecto más homogéneo, en el que difícilmente se identifican los cristales a simple vista esta roca presenta una coloración gris claro verdoso y textura fanerítica.

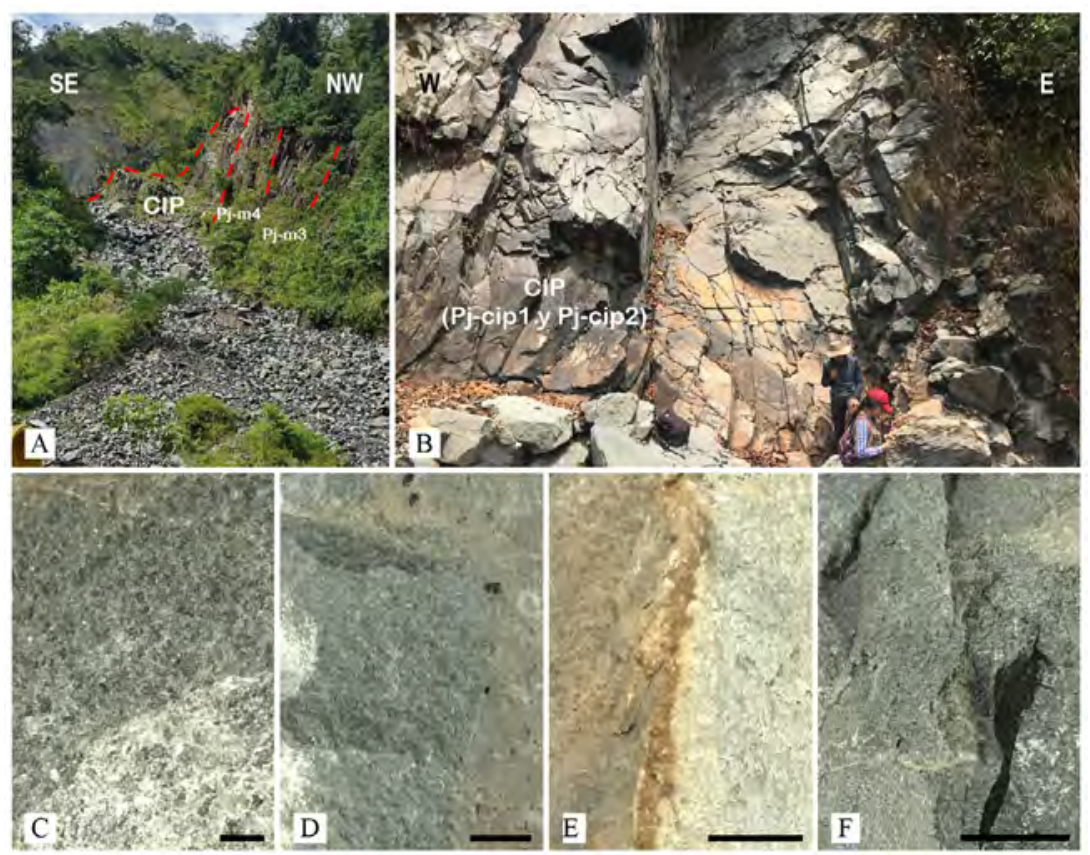

Figura 4. Fotografías del CIP A. Vista de afloramiento del CIP sobre la quebrada La Granja, en línea roja están señalados los contactos con rocas que componen la zonación de alteración metamórfica. B. Fotografía del CIP, roca intensamente fracturada con varias familias de diaclasas. C. CIP, textura de la muestra Pj-cip1 con cristales grandes. D. CIP, textura fanerítica de la muestra Pj-cip2 con cristales alterados que no se identifican a simple vista. E. Textura de la muestra Pj-m4, de la zona de alteración ubicada en contacto al CIP. F. Textura de la muestra Pj-m3, de la zona de alteración periférica ubicada en contacto con la roca sedimentaria encajante.

Macroscópicamente, las texturas de estos cuerpos muestran un origen asociado a procesos intrusivos, teniendo en cuenta que su principal criterio diferencial es el grado de cristalinidad y la clasificación textural según el tamaño absoluto de los cristales, que abarcan texturas fanerítica y porfídica, sin dejar de lado la evidencia de minerales de alteración y texturas de reemplazamiento, que pueden, en algunos casos, volver difusas las texturas primarias de las rocas ígneas y establecer texturas de metasomatismo por esta razón prevalece la clasificación microscópica sobre la macroscópica.

\section{Petrografía}

El análisis petrográfico, realizado sobre ocho secciones delgadas, comprende la identificación de minerales y su composición porcentual a partir de observaciones microscópicas. La Tabla 2 resume los resultados obtenidos de tres de las intrusiones identificadas (intrusión 1, muestra Pj-ia; intrusión 2, muestra Pj-ib; e intrusión 3, muestra Pj-ic), el CIP (muestras Pj-cip1, Pj-cip2 y Pj-m4) y la roca caja en la que se encuentran emplazados la intrusión 1 (muestra Pj-ma) y el CIP (muestra Pj-m3). 
Tabla 2. Composición mineralógica porcentual de los análisis microscópicos.

\begin{tabular}{|c|c|c|c|c|c|c|c|c|c|}
\hline \multicolumn{2}{|c|}{ Análisis microscópico } & \multirow{2}{*}{$\begin{array}{c}\begin{array}{c}\text { Intrusión } \\
1\end{array} \\
\text { Pj-ia }\end{array}$} & \multirow{2}{*}{$\begin{array}{c}\text { Roca } \\
\text { caja }\end{array}$} & \multirow{2}{*}{$\begin{array}{c}\text { Intrusión } \\
\mathbf{2} \\
\mathbf{P j - i b}\end{array}$} & \multirow{2}{*}{$\begin{array}{c}\text { Intrusión } \\
\mathbf{3} \\
\mathrm{Pj} \text {-ic }\end{array}$} & \multicolumn{3}{|c|}{ CIP } & \multirow{2}{*}{$\begin{array}{c}\begin{array}{c}\text { Roca } \\
\text { caja }\end{array} \\
\text { Pj-m3 }\end{array}$} \\
\hline & & & & & & Pj-cip1 & Pj-cip2 & Pj-m4 & \\
\hline \multicolumn{10}{|c|}{ Mineralogía \% } \\
\hline \multirow{8}{*}{ Esencial } & Clinopiroxeno & - & - & - & - & 27 & $\operatorname{Tr}$ & - & - \\
\hline & Moscovita & - & 32 & - & - & - & - & - & - \\
\hline & Ortoclasa & - & 1 & $\operatorname{Tr}$ & 4 & 4 & 2 & 3 & - \\
\hline & Ortopiroxeno & - & - & - & - & 4 & $\operatorname{Tr}$ & - & - \\
\hline & Plagioclasa & - & - & $\operatorname{Tr}$ & 24 & 10 & 6 & - & - \\
\hline & $\begin{array}{c}\text { Matriz } \\
\text { microcristalina }\end{array}$ & - & - & 53 & - & - & - & - & - \\
\hline & $\begin{array}{l}\text { Minerales } \\
\text { arcillosos }\end{array}$ & - & 12 & - & - & - & - & - & 51 \\
\hline & Líticos & - & 6 & - & - & - & - & - & - \\
\hline \multirow[t]{2}{*}{ Secundario } & Cuarzo & 1 & 1 & $\operatorname{Tr}$ & 2 & - & 1 & 1 & 4 \\
\hline & Apatito & 1 & - & $\operatorname{Tr}$ & $\mathrm{Tr}$ & - & 1 & - & - \\
\hline \multirow[t]{8}{*}{ Accesorio } & Circón & $\operatorname{Tr}$ & 1 & $\operatorname{Tr}$ & 1 & 2 & 1 & - & $\operatorname{Tr}$ \\
\hline & Rutilo & - & $\operatorname{Tr}$ & - & $\operatorname{Tr}$ & - & 1 & - & - \\
\hline & Actinolita & $\operatorname{Tr}$ & - & 1 & 1 & - & $\operatorname{Tr}$ & 1 & - \\
\hline & Alunita & $\operatorname{Tr}$ & 2 & $\operatorname{Tr}$ & $\operatorname{Tr}$ & $\operatorname{Tr}$ & - & $\operatorname{Tr}$ & - \\
\hline & Calcita & 22 & 24 & 13 & 23 & 3 & 37 & 50 & 20 \\
\hline & Clorita & 2 & - & 3 & 20 & 17 & 42 & 2 & - \\
\hline & Epidota & 7 & - & - & - & 5 & $\operatorname{Tr}$ & 3 & 1 \\
\hline & Hornblenda & - & - & - & - & 20 & - & - & - \\
\hline \multirow[t]{7}{*}{ Alteración } & Illita & $\operatorname{Tr}$ & - & - & - & - & - & - & - \\
\hline & Minerales opacos & 33 & 11 & 24 & 10 & 2 & 4 & 25 & 22 \\
\hline & Óxido & - & 10 & 1 & - & - & - & - & - \\
\hline & Penina & - & - & $\operatorname{Tr}$ & 7 & - & - & - & - \\
\hline & Sericita & 34 & - & 3 & 4 & - & 5 & 15 & - \\
\hline & Siderita & - & - & 2 & 4 & - & - & - & 2 \\
\hline & Tremolita & - & - & - & - & 6 & - & - & - \\
\hline \multicolumn{2}{|c|}{ Total (\%) } & 100 & 100 & 100 & 100 & 100 & 100 & 100 & 100 \\
\hline
\end{tabular}

A continuación, se presenta la caracterización de cada uno de los intrusivos con énfasis en la caracterización microscópica de minerales principales y de alteración.

Caracterización intrusión 1: la muestra correspondiente a la roca caja, de aspecto metasedimentario (Pj-ma), fue definida como metalimolita arcillosa; además, la muestra expone una presencia accidental de alunita como parte de algunos líticos. En la muestra intrusiva Pj-ia, microscópicamente se identificaron minerales de alteración como sericita, minerales opacos (pirita y calcopirita) y calcita, los cuales dominan porcentualmente la muestra, y epidota y clorita, en menor porcentaje. Presenta una cristalinidad de tipo holocristalino y texturas de alteración como pseudomorfismo, seritización, cloritización y sausuritización, las dos últimas en menor medida (Figura 5A, 5B). Finalmente, se puede decir que la muestra correspondiente a este cuerpo no se puede clasificar mediante los estándares de clasificación de rocas ígneas, dada la alteración hidrotermal pervasiva. 
Caracterización intrusión 2: se determinó un alto porcentaje de minerales de alteración como minerales opacos, calcita, clorita, sericita y actinolita, inmersos en una matriz microcristalina alterada. El grado de cristalinidad aparente en la muestra $\mathrm{Pj-ib}$ es holocristalina, con texturas como pseudomorfismo. Según la Figura 5C, 5D, los minerales opacos podrían corresponder a ferromagnesianos alterados, que exponen formas tabulares alargadas asemejándose a plagioclasas y algunos prismas a manera de piroxenos, con algunos apatitos asociados. No es posible dar una clasificación exacta a causa de la alteración de los minerales.
Caracterización intrusión 3: en la muestra Pj-ic se identificaron minerales primarios como plagioclasa (labradorita - bytownita) y algunos relictos de ortoclasa y cuarzo accidental, así como minerales de alteración: calcita, clorita, minerales opacos, penina, sericita y siderita, los cuales se encuentran dispersos alrededor de la roca en proporciones semejantes y, en menor proporción, alunita y actinolita. Por último, la muestra presenta una cristalinidad de tipo holocristalina y texturas de alteración como pseudomorfismo (sobre cristales de feldespatos potásicos y piroxenos) y cloritización (Figura 5E, 5F).
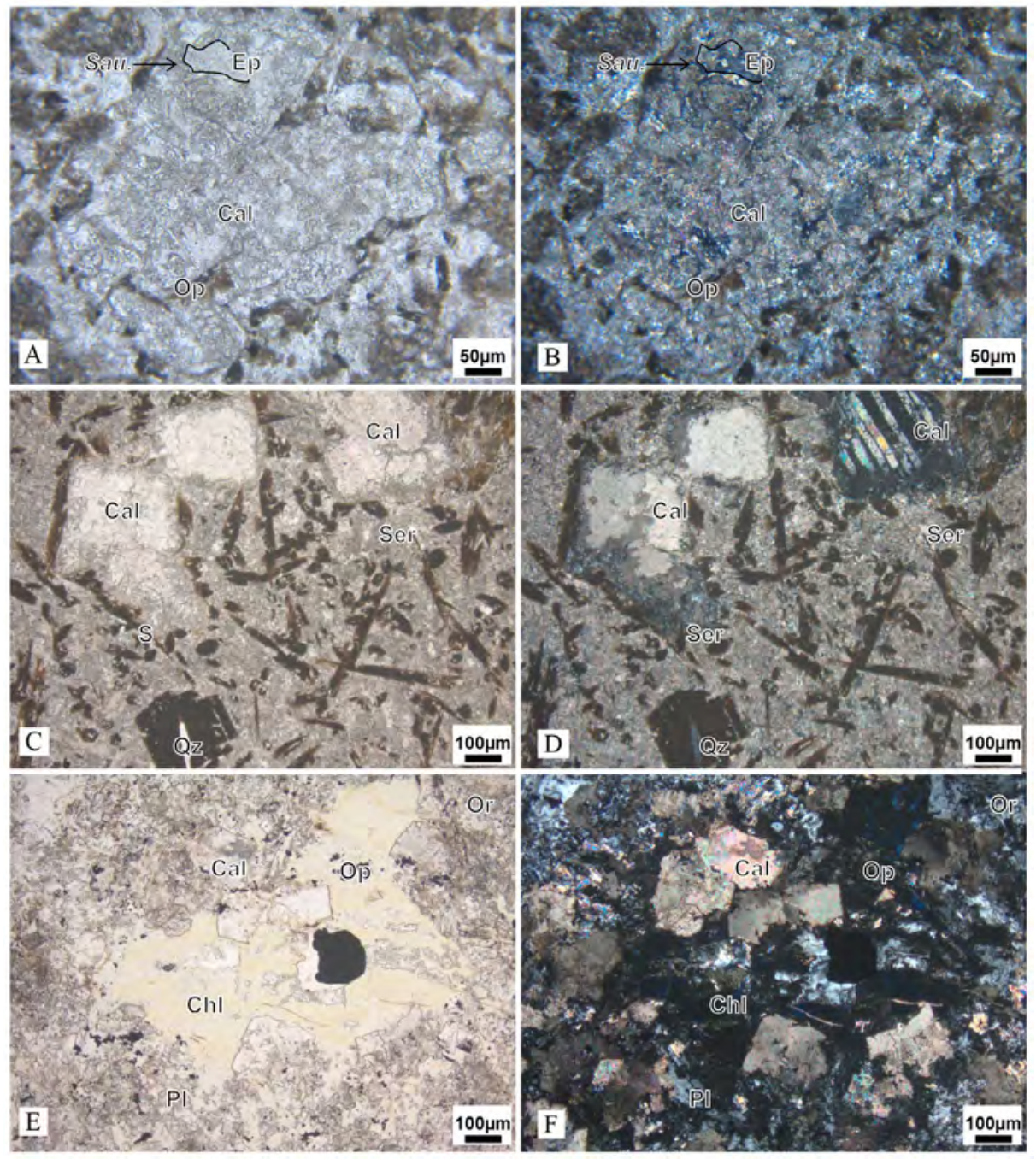

Figura 5. Secciones delgadas de las muestras: A.-B. Pj-ia, C.-D. Pj-ib y E.-F. Pj-ic; a la izquierda nicoles paralelos y a la derecha nicoles cruzados. Las figuras muestran cristales de Cal: calcita, Chl: clorita, Ep: epidota, Op: minerales opacos, Or: ortoclasa, Ser: sericita, Qz: cuarzo. A. Textura de reemplazamiento sausuritización, se resalta el contorno de un cristal de ortosa que está siendo reemplazado parcialmente a epidota. 
Caracterización del CIP: la clasificación petrográfica del cuerpo principal (Pj-cip1) corresponde a una roca melagabronorita (Figura 6), que responde al contenido porcentual de los minerales: clinopiroxeno, ortopiroxeno, plagioclasa (labradorita - bytownita), ortoclasa y minerales de reemplazamiento como hornblenda, clorita, tremolita, epidota y calcita; además se reconocieron las texturas poikilítica (circones sobre hornblenda), lamprofídica, simplectítica y pertitíca, y texturas de reemplazamiento: cloritización, pseudomorfismo (sobre feldespatos potásicos) y uralitización (Figura 7A, 7B, 7C, 7D). En la muestra Pj-cip2 microscópicamente se identificaron minerales de plagioclasa (labradorita), ortoclasa y piroxenos en muy bajas proporciones, mientras que en proporciones dominantes se distinguen minerales de alteración: clorita, calcita, sericita, minerales opacos, epidota y actinolita, además expone textura cumulofídica y texturas de reemplazamiento pseudomorfismo y cloritización (Figura 7E, 7F).

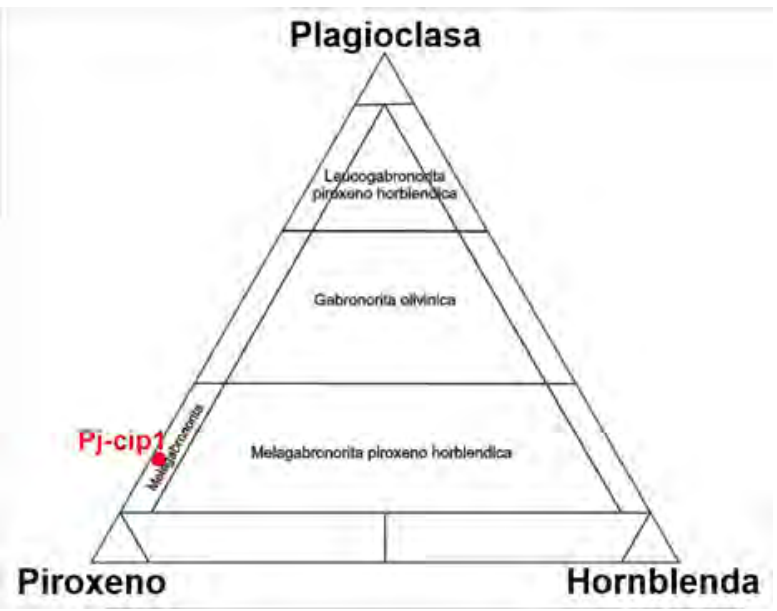

Figura 6. Diagrama de clasificación microscópica para rocas gabroicas holocristalinas con $35-90 \%$ máficos (modificado de Streckeisen, 1976), usado en la clasificación de la muestra Pj-cip1.

Alrededor del cuerpo se distinguieron rocas de diferente composición, muestreadas según Pj-m3 y Pj$\mathrm{m} 4$; la primera roca metasedimentaria fue determinada como roca metalimolita a hornfelsa, de coloración gris moteada, dominada por minerales arcillosos y presencia de cuarzo, además de minerales de alteración: minerales opacos, calcita, siderita y epidota (Figura 8A, 8B). La muestra Pj-m4 (Figura 8C, 8D), de textura homogénea y grado de cristalinidad holocristalina, incluye los minerales esenciales de bajo porcentaje ortoclasa y cuarzo, y minerales de alteración: calcita, minerales opacos, sericita y epidota, con porcentajes trazas de actinolita, clorita y alunita. De igual manera, se describen texturas de reemplazamiento: pseudomorfismo, seritización, sausuritización y borde opacítico.

La Tabla 3 presenta la clasificación de las rocas analizadas de las intrusiones, o que tienen relación con las mismas. En algunas muestras no fue posible la clasificación, a causa de la fuerte alteración experimentada en minerales primarios por procesos hidrotermales. La mayoría de las rocas de los intrusivos fueron clasificadas como ígneas o relacionadas con el producto de la precipitación de soluciones hidrotermales; las rocas muestreadas en el contacto con la roca encajante fueron identificadas como metasedimentarias.

\section{Discusión de resultados}

La inyección magmática que dio origen a las rocas del CIP tuvo lugar en el Aptiano (Vásquez et al., 2010), favorecida por los marcados eventos de rifting continental. En total han sido declarados siete cuerpos intrusivos que acompañan el CIP, para un conjunto de ocho cuerpos cristalinos en Pajarito. En esta investigación se estudiaron seis intrusiones, y existen dos más descritas por Moreno-Murillo et al. (2007). En general, los cuerpos intrusivos manifiestan un origen relacionado con un magma máfico, cristalizado en ambientes entre plutónico a hipoabisal, para este último ambiente, las intrusiones 2, 4 y 5 exponen matriz microcristalina, con texturas porfídicas como consecuencia de los procesos de cristalización fraccionada $\mathrm{y}$ enfriamiento a mayor velocidad, causados por el emplazamiento en fracturas o planos de estratificación dentro de la roca encajante. Las rocas encajantes, en el caso de los cuerpos laminares pequeños de masa calórica reducida (intrusiones 2, 3, 4 y 5), no presentan perturbaciones térmicas considerables, a causa de que las intrusiones tuvieron un mínimo de pérdida de calor por conductividad durante la cristalización del fundido (Llambías, 2008).

Seguidamente, las rocas cristalinas fueron fracturadas, unas más intensamente que otras, causando porosidad secundaria, por la que circularían posteriormente las soluciones hidrotermales o fluidos metasomáticos tardíos, que derivaron probablemente de una fase de subducción antigua (Vásquez y Altenberger, 2005). Estas soluciones migraron y modificaron la composición química de las rocas tanto ígneas como metasedimentarias, en variable proporción e intensidad (Sarmiento-Rojas et al., 2006). Como 
resultado se obtuvo un conjunto de cuerpos cristalinos laminares alterados hidrotermalmente, que exponen texturas de reemplazamiento, así como cristales relacionados. Se puede resaltar, entonces, en el caso del CIP, la presencia de hornblendas prismáticas pseudomórficas, en la textura de reemplazamiento denominada uralitización (Figura 7A, 7B), que podría considerar una reclasificación de la etapa magmática de la roca a una melagabronorita, de acuerdo con el diagrama de clasificación microscópica para rocas gabroideas según Streckeisen (1976) (Figura 6), considerando un porcentaje nulo de anfíboles, como minerales de la etapa magmática en la roca ígnea. De igual manera, en el caso de la intrusión 3 y el área zonalizada en contacto del CIP (muestreada en Pj-m4), los fluidos metasomáticos posmagmáticos originaron, como consecuencia del emplazamiento de soluciones hidrotermales y precipitación de minerales, un reemplazamiento muy penetrante que adiciona componentes químicos en las rocas, por esta razón se consideran rocas metasomáticas.
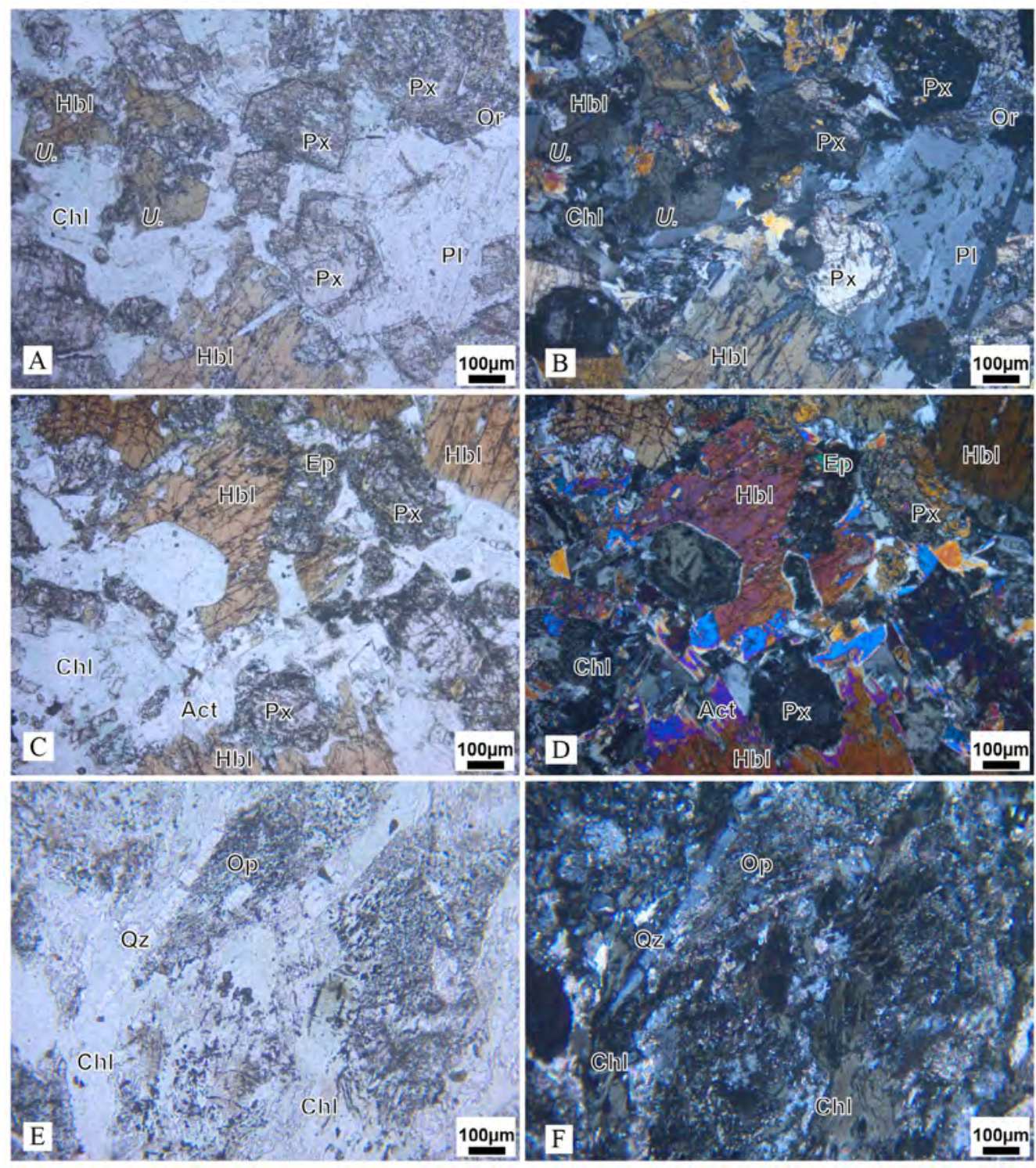

Figura 7. Secciones delgadas de las muestras del CIP: A.-D. Pj-cip1 y E.-F. Pj-cip2; a la izquierda nicoles paralelos y a la derecha nicoles cruzados, se identifican los minerales Act: actinolita, Chl: clorita, Ep: epidota, Hbl: hornblenda, Op: minerales opacos, Px: piroxeno, Pl: plagioclasa, Or: ortoclasa, Qz: cuarzo. A. Se distinguen texturas de intercrecimiento y de reemplazamiento, resaltando la uralitización $(U)$. 


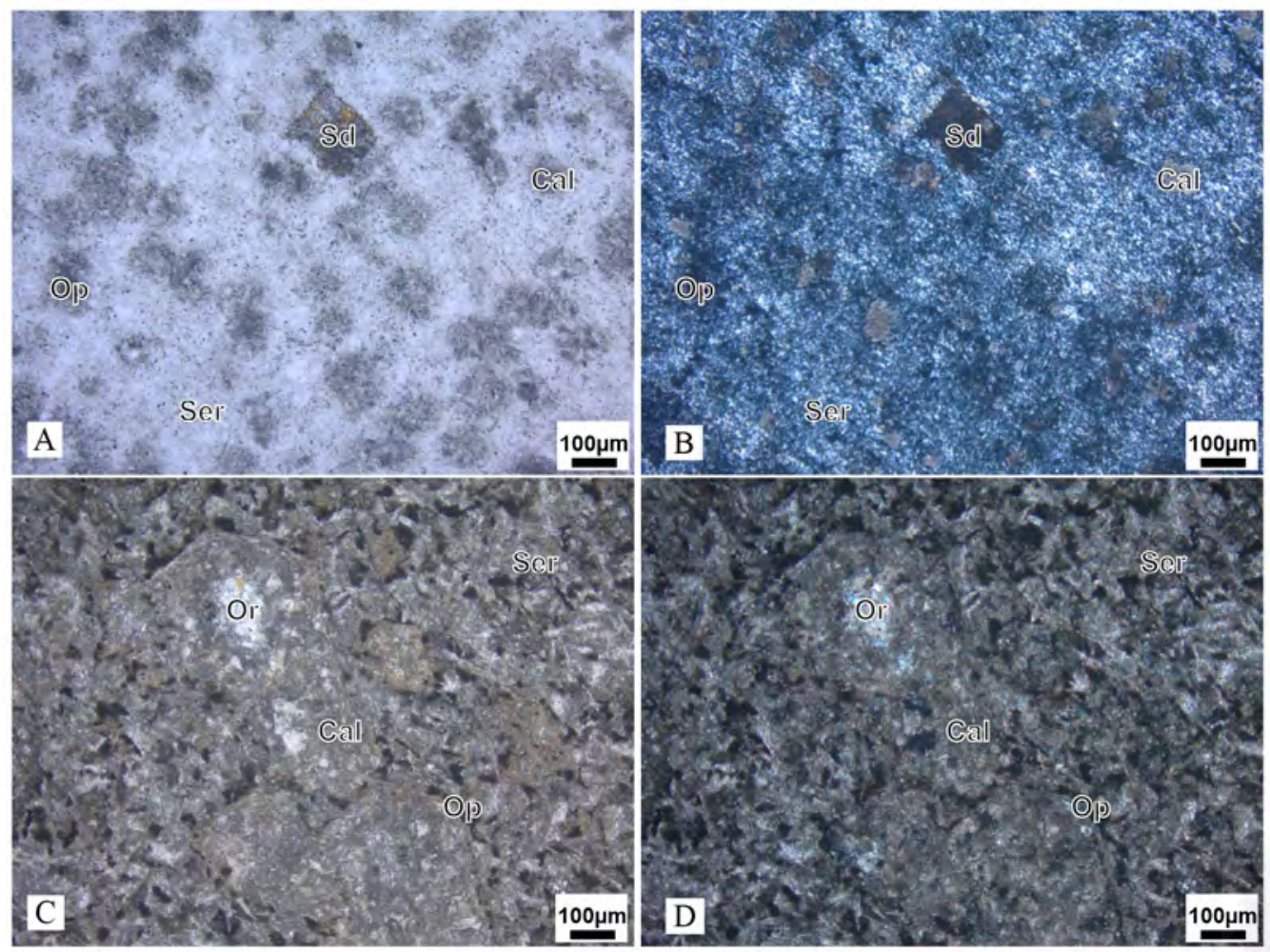

Figura 8. Secciones delgadas de las muestras: A.-B. Pj-m3 y C.-D. Pj-m4; a la izquierda nicoles paralelos y a la derecha nicoles cruzados, se identifican los minerales Cal: calcita, Op: minerales opacos, Or: ortoclasa, Sd: siderita, Ser: sericita. A.-B. Textura moteada intensamente alterada. C.-D. Se aprecia intensidad de alteración pervasiva.

Tabla 3. Clasificación macroscópica y microscópica de las rocas analizadas.

\begin{tabular}{rcccc}
\hline \multirow{2}{*}{ Muestra } & Localización & Tipo de roca & \multicolumn{2}{c}{ Descripción } \\
\cline { 4 - 5 } Pj-ia & Intrusión 1 & Ígnea & Sin identificar & Sin identificar \\
& Contacto & & & Metalimolita \\
Pj-ma & Intrusión 1-Roca & Metasedimentaria & Argilita & arcillosa \\
& caja & & & Sin identificar \\
Pj-ib & Intrusión 2 & Ígnea & Sin identificar & Soluciones \\
Pj-ic & Intrusión 3 & Metasomática & Sin identificar & hidrotermales \\
Pj-id & Intrusión 4 & Ígnea & Sin identificar & - \\
Pj-ie & Intrusión 5 & Ígnea & Sin identificar & - \\
Pj-cip1 & CIP & Ígnea & Gabro & Melagabronorita \\
Pj-cip2 & & Ígnea & Gabro & Melagabronorita \\
Pj-m3 & Contacto CIP- & Metasedimentaria & Metalimolita & Metalimolita \\
Pj-m4 & Roca caja & Metasomática & Sin identificar & Soluciones \\
& & & & hidrotermales \\
\hline
\end{tabular}


Finalmente, en estudios anteriores se ha considerado el tamaño de los cristales del CIP, entre finos y gruesos (ubicados al borde o núcleo del silo, respectivamente), considerando la variación del tamaño como consecuencia del enfriamiento del fundido en la etapa magmática. Sin embargo, teniendo en cuenta el fracturamiento tan intenso de las rocas cristalinas y la alteración hidrotermal pervasiva que experimentó la muestra Pj-cip2, en este estudio se considera el tamaño de los cristales un carácter circunstancial, relacionado con la intensidad de la alteración, que fue condicionada por el fracturamiento de las rocas ígneas en los eventos posmagmáticos, que permitió los cambios de la intensidad de la alteración entre incipientes (Pj-cip1) y pervasivos (Pj-cip2).

\section{Consideraciones de la alteración hidrotermal}

La influencia hidrotermal sobre las muestras de las intrusiones de Pajarito es global y manifiesta alteraciones considerablemente fuertes e incluso pervasivas de magnitudes superiores a lo que se ha considerado en estudios previos sobre las mismas rocas ígneas. Como producto de la interacción química de las soluciones, fueron identificados en el microscopio minerales de reemplazamiento relacionados con una paragénesis mineral, que, determinan un grupo de condiciones de equilibrio fisicoquímico generando una zonación espacial y sincrónica (Meza, 2007), relacionados con una alteración tipo, definida según la Tabla 4.

Tabla 4. Minerales de alteración hidrotermal asociados, identificados en los análisis microscópicos.

\begin{tabular}{|c|c|c|c|c|}
\hline Muestra & Nombre & Tipo de roca & $\begin{array}{l}\text { Asociación de minerales de alteración } \\
\text { hidrotermal (paragénesis) }\end{array}$ & Alteración tipo \\
\hline Pj-ia & Intrusión 1 & Ígnea & $\begin{array}{l}\text { Sericita, minerales opacos (calcopirita/ } \\
\text { pirita), calcita, illita }\end{array}$ & Fílica/sericítica \\
\hline $\mathrm{Pj}-\mathrm{ma}$ & & Metamórfica & - & - \\
\hline Pj-ib & Intrusión 2 & Ígnea & $\begin{array}{l}\text { Opacos (minerales arcillosos con hierro), } \\
\text { calcita, actinolita, clorita, sericita }\end{array}$ & Propilítica \\
\hline Pj-ic & Intrusión 3 & Metasomática & $\begin{array}{l}\text { Calcita, clorita, minerales opacos, penina, } \\
\text { actinolita }\end{array}$ & Propilítica \\
\hline Pj-cip1 & & Ígnea & $\begin{array}{l}\text { Clorita, hornblenda, epidota, tremolita, } \\
\text { minerales opacos (pirita), calcita }\end{array}$ & Propilítica \\
\hline Pj-cip2 & CIP & Ígnea & $\begin{array}{l}\text { Calcita, sericita, clorita, minerales opacos } \\
\text { (pirita), epidota, actinolita }\end{array}$ & Propilítica \\
\hline $\mathrm{Pj}-\mathrm{m} 3$ & & Metamórfica & Calcita, epidota & Propilítica \\
\hline $\mathrm{Pj}-\mathrm{m} 4$ & & Metasomática & $\begin{array}{l}\text { Sericita, calcita, minerales opacos (pirita), } \\
\text { epidota, actinolita, clorita }\end{array}$ & Propilítica \\
\hline
\end{tabular}

Se determinó que las rocas de las intrusiones 2, 3 y CIP están dominadas por la alteración propilítica, que establece una relación genética entre los minerales calcita - clorita - epidota. Esta alteración está generada a partir de las reacciones de hidrólisis, metasomatismo de hidrógeno, hidratación $\mathrm{y}$, dominantemente sobre las muestras, carbonatación (Chirif, 2017; Palacio y Godeas, 2008), que, en consecuencia, exponen texturas de reemplazamiento, comprendidas localmente como pseudomorfismo de feldespatos, reemplazamiento por clorita (cloritización) y uralitización. La alteración hidrotermal propilítica contempla baja razón agua/roca, pH neutro - alcalino y tiende a ser isoquímica; además, las temperaturas de formación o reemplazamiento de los minerales están alrededor de los $200^{\circ} \mathrm{C}$, y puede llegar a los $300^{\circ} \mathrm{C}$, establecido por la presencia de actinolita, formada en una zona interna de mayor temperatura (Corbett y Leach, 1998; Thompson y Thompson, 1996; Palacio y Godeas, 2008). Por el contrario, la intrusión 1 se caracteriza por el dominio de sericita en la roca, relacionada con la alteración sericítica, acompañada por pirita, calcita y minerales arcillosos (illita) y en menor proporción epidota y clorita. Este tipo de alteración es producida por la hidrólisis de feldespatos, que consecuentemente expone texturas de reemplazamiento como pseudomorfismo, 
seritización y sausuritización. En esta roca se observó una estrecha relación entre la calcita y epidota como minerales de reemplazamiento de plagioclasas, relacionado probablemente con el aporte de calcio de las plagioclasas durante los procesos de intercambio químico (Morad et al., 2009). La alteración sericítica o fílica ocurre de forma pervasiva, en condiciones entre neutras a ligeramente ácidas ( $\mathrm{pH} 4-6)$, considerando temperaturas entre $200-250^{\circ} \mathrm{C}$, que reflejan la formación de cristales finos de moscovita (sericita) (Corbett y Leach, 1998; Thompson y Thompson, 1996; Palacio y Godeas, 2008).

La alunita, por otro lado, fue identificada con un porcentaje traza en las muestras $\mathrm{Pj}$-ia, $\mathrm{Pj}$-ib, $\mathrm{Pj}$ ic, Pj-cip1 y $\mathrm{Pj}$-m4, ubicada parcialmente sobre algunos cristales o rellenando microfracturas. Este mineral hace referencia a una alteración hidrotermal extremadamente ácida y de altas temperaturas, que contrastaría con las condiciones de equilibrio fisicoquímico, establecidas anteriormente para los dos tipos de alteración sobre las intrusiones. Por esta razón, en esta investigación la alunita se considerará de origen posalteración, relacionada con un origen tardío supergénico, establecido por Palacio y Godeas (2008), como consecuencia de la oxidación atmosférica de sulfuros sin relación con los sistemas hidrotermales.

Por el contrario, fueron identificados dos puntos, en los que es visible la afectación metamórfica o hidrotermal en la roca caja: la intrusión 1 y el CIP. La dispersión de la alteración en el primer punto no es visible microscópicamente, las apreciaciones que se pueden determinar se manifiestan físicamente en el metamorfismo de bajo grado de la roca lutítica con aspecto pizarroso. Sin embargo, en la roca caja del CIP, la muestra $\mathrm{Pj}-\mathrm{m} 3$ expone un metamorfismo de mayor grado, que modificó la apariencia de la roca sedimentaria dándole un aspecto moteado y aportando un enriquecimiento de minerales de origen hidrotermal, como calcita y epidota. Posiblemente la dispersión de los fluidos hidrotermales y sus minerales asociados tenga una mayor influencia sobre la roca caja, sin embargo, en este estudio no fueron considerados.

\section{Consideraciones preliminares de los yacimientos relacionados con la alteración hidrotermal}

El territorio colombiano se encuentra distribuido sobre dos de los ambientes geológicos más promisorios para la prospección de depósitos minerales: el escudo de Guyana y el Cinturón Circunpacífico o Sistema Andino; esto lo convierte en un país privilegiado en cuanto a la exploración de yacimientos, que van desde el Precámbrico hasta el Cenozoico. El sector que comprende la cordillera Oriental está ubicado dentro de la provincia Metalogénica Central o provincia Metalogénica Andina Oriental; con una historia orogénica y metalogénica compleja, dada la superposición de dos eventos durante el Jurásico - Triásico y el Neógeno, donde el potencial metalogénico se incrementó. La cordillera Oriental sobre el departamento de Boyacá y sus alrededores está dominada por manifestaciones minerales de rocas industriales, relacionadas con calizas y mármoles, y depósitos de fósforo, sin embargo, resaltan el distrito minero de hierro en Paz del Río e importantes distritos mineros de esmeraldas acompañados por pequeños depósitos de plomo y zinc (Pb-Zn) en Muzo - Coscuez (Cinturón Esmeraldífero Occidental) y en Chivor (Cinturón Esmeraldífero Oriental) (Buenaventura, 2001; Celada et al., 2016).

La discutida génesis de las esmeraldas cenozoicas colombianas, obtenidas en los dos distritos mineros de ambos flancos de la cordillera Oriental, está definida según el modelo hidrotermal - sedimentario, relacionado con la formación de fluidos hidrotermales alcalinos, generados en salmueras calientes provenientes de la cuenca. Los fluidos hidrotermales reaccionaron con la materia orgánica de las lutitas durante la reducción termoquímica, generando un aporte de carbonatos a la solución enriquecida en sulfato, sodio, calcio y magnesio, para posteriormente, causar un fracturamiento hidráulico que provocó los bolsones, brechas y venas, donde fueron emplazados los cristales de esmeraldas asociados a la paragénesis calcita + berilo \pm dolomita \pm albita, que además es acompañada por elementos de tierras raras, emplazados en las rocas lodolíticas de la Formación Muzo (correlacionable con la Formación Lutitas de Macanal) (Gómez, 2007; Meza, 2007; Verbel-Olarte, 2017). Sin embargo, Guerrero et al. (2020) han cuestionado fuertemente este modelo, a razón de que no ha sido claro el aporte de los elementos químicos escandio, vanadio y berilio, relacionados con el proceso de formación de las esmeraldas. Por el contrario, argumentan que estos elementos no son introducidos por el aporte de sedimentos a la cuenca, sino a causa de la actividad hidrotermal que sufrieron los cuerpos básicos de la cordillera Oriental, que produjeron la solución mineralizante formadora de esmeraldas, emplazada durante el Cretácico, contrario a lo que se había planteado con anterioridad. 
En vista de ello, en el área de Pajarito pueden existir condiciones geológicas favorables para la existencia de depósitos importantes, relacionados con eventos metalogénicos sobre el Sistema Andino. Se podría considerar que el emplazamiento de las manifestaciones ígneas causó un gradiente geotérmico elevado, que favoreció la circulación de fluidos hidrotermales a través de las rocas cristalinas, provocando un enriquecimiento sobre el CIP en $\mathrm{Ca}, \mathrm{Na}, \mathrm{Al}$ y $\mathrm{Si}$, y que a su vez causó la remoción de iones de $\mathrm{Pb}, \mathrm{Zn}$, $\mathrm{Cu}, \mathrm{Ba}, \mathrm{Fe}$ y Rb (Fabre y Delaloye, 1983; SarmientoRojas, 2002; Vásquez et al., 2007; Moreno-Murillo et al. 2007); en este sentido, a manera de hipótesis, el presunto fluido hidrotermal tendría un gran potencial mineralizante, debido a la asimilación de elementos metálicos importantes, que pudieron haber sido precipitados en una trampa geoquímica. De la misma forma, Vásquez et al. (2010) argumentan que el magma que generó las rocas plutónicas en el CIP estuvo enriquecido por tierras raras (REE), lo que favorece el posible enriquecimiento de la hipotética solución mineralizante. Para concluir, es importante ampliar el rango de investigación sobre el área, incluyendo un muestreo más completo en las rocas cristalinas, rocas sedimentarias y venas hidrotermales, donde se apliquen análisis petrográficos, de espectrometría por fluorescencia de rayos X o microsonda, que podrían definir una zonación de alteraciones hidrotermales tipo o incluso la existencia de una mineralización.

\section{Conclusiones}

Los minerales de la etapa magmática que fueron identificados en el CIP comprenden clinopiroxeno, ortopiroxeno, plagioclasa (labradorita - bytownita) y ortoclasa, que permitieron dar una clasificación aproximada de la muestra, definida como una melagabronorita. Por el contrario, las rocas muestreadas de la intrusión 1 a la intrusión 5 no permiten dilucidar una clasificación que corresponda con la etapa magmática para ninguno de los cuerpos cristalinos, sin embargo, manifiestan una textura dominantemente porfídica, relacionada con eventos de cristalización fraccionada.

Gran proporción de las rocas ígneas fue alterada composicionalmente debido a la circulación de fluidos hidrotermales, que modificaron la mineralogía de las intrusiones, cambiando los caracteres magmáticos evaluados de las muestras, entre ellos, composición, estructuras y texturas originales de la roca, lo cual se evidencia en texturas de reemplazamiento y minerales asociados. Según los análisis microscópicos, la muestra con alteración más pervasiva es la Pj-cip2 del CIP, en donde fortuitamente fueron identificadas las texturas de la etapa magmática; es evidente que la alteración hidrotermal penetró y destruyó completamente los caracteres de la roca, y su clasificación petrográfica sería errónea de no ser por la relación genética con la muestra Pj-cip1. Por otro lado, la muestra de la intrusión 3 (Pj-ic) y la muestra en contacto al CIP (Pj-m4) fueron determinadas como rocas metasomáticas, debido al fuerte intercambio químico que ocurrió entre la solución hidrotermal y la roca.

En cuanto a los resultados obtenidos de las alteraciones hidrotermales tipo, se estableció que los eventos que modificaron el conjunto de intrusiones de Pajarito estuvieron dominados por soluciones de bajas temperaturas, definidas de acuerdo a dos paragénesis identificadas: primero, la paragénesis sericita - pirita calcita, relacionada con un $\mathrm{pH}$ entre neutro a ligeramente ácido, y, segundo, la paragénesis calcita - clorita epidota - actinolita en zonas de pH neutro a básico.

La inyección magmática que dio origen a las intrusiones tuvo lugar en el Aptiano, donde la influencia magmática provocó en las rocas sedimentarias encajantes la formación de una aureola de metamorfismo conformada por metalimolitas, argilitas y en otros casos no se manifestaron perturbaciones significativas. Por otro lado, la influencia hidrotermal posterior se manifestó en las rocas encajantes analizadas, como trazas de minerales de alteración e influencia débil aparentemente.

Finalmente, se hace mención de un hipotético fluido mineralizante, relacionado con las soluciones hidrotermales enriquecidas por la lixiviación de elementos metálicos dentro de las rocas intrusivas.

\section{Agradecimientos}

Los autores agradecen a la Universidad Pedagógica y Tecnológica de Colombia, sede Sogamoso, por facilitar el proceso de análisis y la creación de secciones delgadas, y a Carlos Vargas, por su ayuda en la revisión de las muestras; de igual manera, nuestros más sinceros agradecimientos a los revisores Jairo Conde Gómez y Ana Elena Concha Perdomo, y demás personas involucradas, por su disposición y colaboración. Finalmente, a la comunidad pajariteña por permitirnos investigar sobre su territorio. 


\section{Referencias}

Buenaventura, J. (2001). Posibilidades metalogénicas auríferas en el territorio colombiano. VIII Congreso Colombiano de Geología. Manizales, Colombia.

Canchón-Acuña, D.M.; Concha-Perdomo, A.E.; Moreno-Murillo, J.M. (2014). Caracterización petrográfica y geoquímica del cuerpo intrusivo de Guaquimay (Cundinamarca) Colombia. Geología Colombiana, 39, 23-35.

Celada, C.M.; Luengas, C.; Velásquez, L.; Prieto, D.; Cáceres, A.; Sepúlveda, J.; López, J.; Moyano, I.; Prieto, G. (2016). Mapa Metalogénico de Colombia. Servicio Geológico Colombiano. Comprende mapa escala 1:1.500.000.

Chirif, H. (2017). Alteraciones Hidrotermales. Material de curso.

Corbett, G.J.; Leach, T.M. (1998). Southwest Pacific rim gold-copper systems: Structure, alteration and mineralization. Society of Economic Geologist.

Durán-González, S.; González-Preciado, A.J. (2019). Análisis estratigráfico y reconstrucción paleoecológica de la Formación Lutitas de Macanal en la sección aflorante del municipio de Pajarito, Boyacá. Tesis, Universidad Pedagógica y Tecnológica de Colombia, Colombia.

Dengo, C.A.; Covey, M.C. (1993). Structure of the Eastern Cordillera of Colombia: implications for trap styles and regional tectonics. AAPG Bulletin, 77(8), 1315-1337. https://doi.org/10.1306/ BDFF8E7A-1718-11D7-8645000102C1865D

Fabre, A.; Delaloye, M. (1983). Intrusiones básicas cretácicas en las sedimentitas de la parte central de la Cordillera Oriental. Geología Norandina, 6, 19-28.

Gómez, C. (2007). Estudio de los procesos de alteración hidrotermal en rocas del HauterivianoBarremiano (Cretácico Inferior) del túnel 'Chirripay', Sector esmeraldífero Yacopí, Cundinamarca. Tesis, Universidad Industrial de Santander, Bucaramanga, Colombia.

Guerrero, J.; Mejia-Molina, A.; Osorno, J. (2020). Detrital U-Pb provenance, mineralogy, and geochemistry of the Cretaceous Colombian backarc basin. In: J. Gómez, A.O. Pinilla-Pachón (eds.). The Geology of Colombia (pp. 261-297). Servicio Geológico Colombiano. https://doi. org/10.32685/pub.esp.36.2019.08

Huang, W.T. (1991). Petrología. UTEHA.

INGEOMINAS (2010). Geología del Piedemonte Llanero en la Cordillera Oriental, Departamentos de Arauca y Casanare. Bucaramanga, Colombia. Instituto Nacional de Investigaciones GeológicoMineras - Ministerio de Minas y Energía.

Irving, E.M. (1971). La evolución estructural de los Andes más septentrionales de Colombia. Boletín Geológico, 19(2), 1-90.

Jaillard, E.; Soler, P.; Carlier, G.; Mourier, T. (1990). Geodynamic evolution of the northern and central Andes during early to middle Mesozoic times: a Tethyan model. Journal of the Geological Society, 147(6), 1009-1022. https://doi.org/10.1144/ gsjgs.147.6.1009

Llambías, E.J. (2008). Geología de los Cuerpos Ígneos. Asociación Geológica Argentina.

Meza, J.A. (2007). Estudio de las manifestaciones hidrotermales del túnel ‘La Paz’ (Vereda Coscuez, Municipio esmeraldífero de San Pablo de Borbur, Boyacá). Tesis, Universidad Industrial de Santander, Bucaramanga, Colombia.

Morad, S.; El-Ghali, M.A.K.; Caja, M.A.; Sirat, M. Al-Ramadan, K.; Mansurbeg, H. (2009). Hydrothermal alteration of plagioclase in granitic rocks from Proterozoic basement of SE Sweden. Geological Journal, 45(1), 105-116. https://doi. org/10.1002/gj.1178

Moreno-Murillo, J.M.; Concha-Perdomo, A.E.; Lozano, E.L. (2007). Petrogénesis y geoquímica del cuerpo ígneo de Pajarito, Boyacá - Colombia. Geología Colombiana, 32, 111-126.

Navarrete-Rodríguez, A.T.; Moreno-Murillo, J.M.; Concha-Perdomo, A.E.; Patarroyo-Gama, P. (2002). Interpretación petrogenética del Gabro de Tragarepas al norte de Pacho - Cundinamarca, Colombia. Geología Colombiana, 27, 109-120. 
Palacio, M.B.; Godeas, M. (2008). Guía de Minerales de Alteración de la República Argentina. Instituto de Geología y Recursos Minerales, SEGEMAR.

Pindell, J.L.; Erikson, J.P. (1994). The Mesozoic Passive Margin of Northern South America. In: J.A. Salfity (ed.). Cretaceous Tectonics of the Andes (pp. 1-60). Teubner Verlag. https://doi. org/10.1007/978-3-322-85472-8_1

Piraquive, A.; Díaz, J.S.; Cuellar, T.; Pardo, G.; Kammer, A. (2011). Reactivación Neógena de estructuras de rift del Cretácico Temprano asociadas con la Falla de Chámeza, Pajarito, Boyacá (Colombia): evidencias tectónicas y bioestratigráficas. Geología Colombiana, 36(1), 197-216.

Ramos, V.A. (2009). Anatomy and global context of the Andes: Main geologic features and the Andean orogenic cycle. In: S.M. Kay, V.A. Ramos, W.R. Dickinson (eds.). Backbone of the Americas: Shallow subduction, plateau uplift, and ridge and terrane collision (pp. 31-65). Vol. 204. The Geological Society of America. https:// doi.org/10.1130/2009.1204(02)

Roa-Castro,M.B.;Rojas-Avella,N.A.(1992).Evaluación de la capacidad generadora de hidrocarburos de las lutitas y calizas cretáceas del flanco oriental de la Cordillera Oriental - Departamento de Boyacá. Tesis de Pregrado, Universidad Pedagógica y Tecnológica de Colombia.

Sarmiento-Rojas, L.F. (2002). Condiciones geológicas favorables de las sedimentitas Cretácicas de la Cordillera Oriental de Colombia para la existencia de depósitos exhalativos submarinos de plomo y zinc. Boletín de Geología, 24(39), 50-72.

Sarmiento-Rojas, L.F.; Van Wess, J.D.; Cloetingh, S. (2006). Mesozoic transtensional basin history of the Eastern Cordillera, Colombian Andes: Inferences from tectonic models. Journal of South American Earth Sciences, 21(4), 383-411. https:// doi.org/10.1016/j.jsames.2006.07.003

Saylor, J.E.; Horton, B.K.; Stockli, D.F.; Mora, A.; Corredor, J. (2012). Structural and thermochronological evidence for Paleogene basement-involved shortening in the axial Eastern Cordillera, Colombia. Journal of South
American Earth Sciences, 39, 202-215. https:// doi.org/10.1016/j.jsames.2012.04.009

Streckeisen, A. (1976). To each plutonic rock its proper name. Earth-Science Reviews, 12(1), 1-33. https://doi.org/10.1016/0012-8252(76)90052-0

Tesón, E.; Mora, A.; Silva, A.; Namson, J.; Teixell, A.; Castellanos, J.; Casallas, W.; Julivert, M.; Taylor, M.; Ibañez-Mejía, M.; Valencia, V.A. (2013). Relationship of Mesozoic graben development, stress, shortening magnitude, and structural style in the Eastern Cordillera of the Colombian Andes. Geological Society, London, Special Publications, 377, 257-283. https://doi.org/10.1144/SP377.10

Thompson, A.J.B.; Thompson, J.F.H. (1996). Atlas of Alteration. Geological Association of Canada.

Ulloa, C.; Rodríguez, E. (1981). Geología del cuadrángulo K-13, Tauramena. Boletín Geológico, 24(2), 5-30.

Ulloa, C.; Rodríguez, E.; Fuquen, J.; Acosta, J.E. (2001). Geología de la Plancha 192. INGEOMINAS.

Vásquez, M.; Altenberger, U. (2005). Mid-Cretaceous extension-related magmatism in the Eastern Colombian Andes. Journal of South American Earth Sciences, 20(3), 193-210. https://doi. org/10.1016/j.jsames.2005.05.010

Vásquez, M.; Wilke, M.; Altemberger, U.; Rickers, K. (2007). Trace elements content of clinopyroxenes and amphiboles in gabbros of the Colombian Andes - Possible constraints for the magma source. In: M. Vásquez (ed.). Mafic magmatism in the Eastern Cordillera and Putumayo basin, Colombia: Causes and consequences (pp. 33-66). Universität Potsdam.

Vásquez, M.; Altenberger, U.; Romer, R.L.; Sudo, M.; Moreno-Murillo, J.M. (2010). Magmatic evolution of the Andean Eastern Cordillera of Colombia during the Cretaceous: Influence of previous tectonic processes. Journal of South American Earth Sciences, 29(2), 171-186. https:// doi.org/10.1016/j.jsames.2009.02.003

Verbel-Olarte,A.A.(2017). Mineralogía de elementos de tierras raras en las mineralizaciones esmeraldíferas 
colombianas. MSc. Tesis, Universidad Nacional de Colombia, Bogotá, Colombia.

Zapata, S.; Cardona, A.; Jaramillo, J.S.; Patiño, A.; Valencia, V.; León, S.; Mejía, D.; Pardo-Trujillo, A.; Castañeda, J. P. (2019). Cretaceous extensional and compressional tectonics in the Northwestern
Andes, prior to the collision with the Caribbean oceanic plateau. Gondwana Research, 66, 207226. https://doi.org/10.1016/j.gr.2018.10.008

Fecha de recibido: 25 de septiembre de 2020

Fecha de aprobado: 06 de septiembre de 2021 